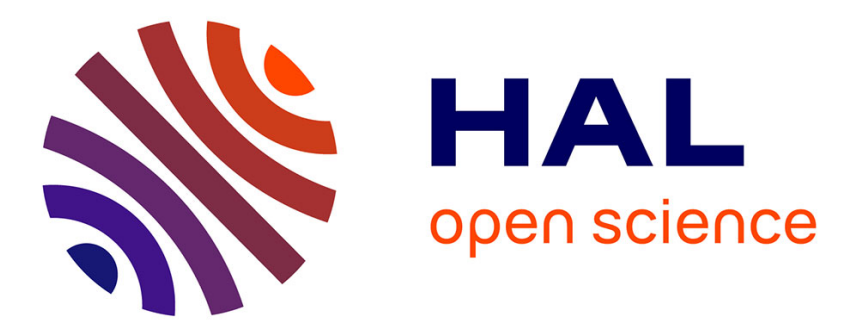

\title{
The Study of the Boron Nitride Thin Layer Structure
}

\author{
G. Yuryev, E. Maximovskiy, Yu. Rumyantsev, N. Fainer, M. Kosinova
}

\section{To cite this version:}

G. Yuryev, E. Maximovskiy, Yu. Rumyantsev, N. Fainer, M. Kosinova. The Study of the Boron Nitride Thin Layer Structure. Journal de Physique IV Proceedings, 1995, 05 (C5), pp.C5-695-C5-698. 10.1051/jphyscol:1995583 . jpa-00253945

\section{HAL Id: jpa-00253945 https://hal.science/jpa-00253945}

Submitted on 1 Jan 1995

HAL is a multi-disciplinary open access archive for the deposit and dissemination of scientific research documents, whether they are published or not. The documents may come from teaching and research institutions in France or abroad, or from public or private research centers.
L'archive ouverte pluridisciplinaire HAL, est destinée au dépôt et à la diffusion de documents scientifiques de niveau recherche, publiés ou non, émanant des établissements d'enseignement et de recherche français ou étrangers, des laboratoires publics ou privés. 


\title{
The Study of the Boron Nitride Thin Layer Structure
}

\author{
G.S. Yuryev, E.A. Maximovskiy, Yu.M. Rumyantsev, N.I. Fainer and M.L. Kosinova \\ Institute of Inorganic Chemistry, Siberian Branch of the Russian Academy of Sciences, \\ 630090 Novosibirsk, Russia
}

\begin{abstract}
The structure of thin layers of boron nitride obtained by low temperature plasma enhanced chemical vapour deposition of borazine as precursor has been investigated by $\mathrm{X}$-ray diffraction method. The diffraction pattern consists of the superposition of the three patterns: from non-crystalline turbostrate am-BN, from polycrystalline h-BN and c-BN. The sizes of intermolecular (nucleus surrounded by "fringe"), $14.8 \AA$, and intramolecular (nucleus), $7.6 \AA$, formations are evaluated from the reflection positions in non-crystalline state and confirmed by calculation. Polycrystalline reflections from $\mathrm{h}-\mathrm{BN}$ and $\mathrm{c}-\mathrm{BN}$ are in accordance with known ones for these modifications.
\end{abstract}

\section{INTRODUCTION}

Boron nitride (BN) is one of the most interesting materials of the III-V compounds, from both a practical and a fundamental scientific view point due to its low density, high thermal conductivity, chemical inertness, very high hardness and high resistivity. There are a wide variety of techniques for preparation of $B N$ thin films. Recently the remote plasma enhanced chemical vapour deposition (RPECVD) became one of the most important technique of thin layers growth. A potentially interesting precursor for $B N$ film production is the borazine $\left(\mathrm{B}_{3} \mathrm{~N}_{3} \mathrm{H}_{6}\right)$ which contains the exact ratio of $\mathrm{B}: \mathrm{N}=1: 1$ and hydrogen as the only foreign atom.

Synthesis of thin layers of BN by RPECVD using borazine allowed to produce films at temperatures considerably below than in convenient CVD. Considerable recent attention has been focussed on the structure investigations of boron nitride thin films because the physical and chemical properties of these layers strong depend on structure type[1]. In this paper we investigate the structure of boron nitride layers by $x$-ray diffraction method.

\section{EXPERIMENT}

The films were grown from the mixture of borazine and helium by RPECVD method [2] on $\mathrm{Si}$ (100) single crystal substrates. The synthesized films were characterized by different techniques. The thickness (150-170 nm) and refractive index $(1.6-1.7)$ of the films were determined from ellipsometric measurements at $\lambda$ $=632.8 \mathrm{~nm}$. IR spectroscopy was used for a control of chemical composition of these layers. 
The experimental diffraction patterns as Iexp ( $2 \Theta)$ from the sample surface were recorded on $X$ ray diffractometer DRON 4 [3] with the automated one circle (detector) and the rotation of the sampled studied relative to the incident radiation. The complete intensity curve was recorded three times with set of $10^{5}$ counts for 7-12 minutes in each point of diffraction space. The pasition of the diffraction peaks were determined by scanning in narrow range of angles with $2 \Theta=0.1^{\circ}$ steps. Systematic error in the intensity measurements dependent on the value of the diffraction angle was eliminated by matching the vertical slit widths during shaping incident radiation, as an example, when the slit width will be doubled the intensity measured in each point of the diffraction space will also be doubled.

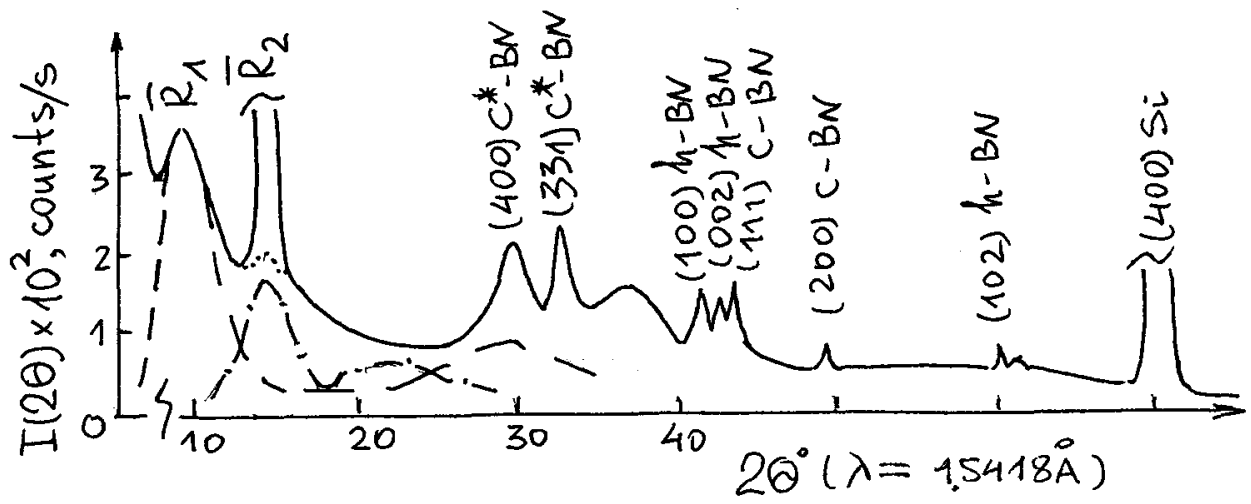

Figure 1: Diffraction pattern of $B N$ film obtained under automatic operation. The value $R_{1}$ is determined from the location $\mathrm{k} 1$ of the main reflection in the intermolecular scattering (dashed line, calculated using eq.1). The value $\mathrm{R} 2$ is determined from the location $\mathrm{k} 2$ of the main reflection in the intramolecular scattering (dashed-and-dotted line, calculated using eq.2). The dotted line gives the main peak intensity of the intramolecular scattering vanishing when the sample rotating relative to the incident radiation (lexture). The reflections from $c-B N$ correspond to those of a supercell with the parameter of $a^{*}=4 a$ (a is the parameter of cell of $c-B N)$. The reflections from $h-B N$ and $c-B N$ correspond to known in $[4,5]$.

The experimental pattern consisted of three patterns: one from am-BN and two from polycrystalline hexagonal $h-B N$ and cubic $c-B N$. The $h-B N$ and $c-B N$ reflections have been identified by us according to reported in Refs. $[4,5]$. Appropriate corrections dependent on the properties of radiation and material [6] were introduced into experimental diffraction patterns. In the case of amorphous boron nitride (am-BN) a procedure of the intensity normalization (obtaining $I_{\mathrm{exp}}^{\text {nurm }}(k)$ ) involved matching two modified (by $\mathrm{k}^{2}, k=(4 \pi / \lambda) \sin \Theta, \ddot{A}^{-1} ; \lambda$ $=1.5418 \quad \ddot{A}, \Theta$ being half the Bragg scattering angle) scatterings, namely, experimental $I \exp (k)$ and gaseous $I_{\text {gas }}(k)=$ $\sum_{i=1}^{N} n_{i} f_{i}{ }^{2}(k)$, where $\mathrm{N}$ and $\mathrm{n}_{\mathrm{i}}$ are the numbers of atom kinds and atoms of each kind, respectively, in the formula unit of $\mathrm{BN}$ substance; $f(k)$ is the tabulated atomic factor of scattering [7]. The reability of this procedure was confirmed by that the normalization coefficient was practically unchanged with 
increase of $k_{\max }$ defining the cut-off of experimental data on the high angle side. The total ( $t$ ) pattern from am-BN can be represented as the sum of intermolecular (int) and intramolecular (in) scattering [8]:

$$
S_{t}(k)=S_{i n}(k)+F(k)\left\{S_{i n t}(k)-1\right\}
$$

where $\mathrm{S}(\mathrm{k})=I_{\text {exp }}^{\text {norm }}(k) / \mathrm{I}_{\text {gas }}(\mathrm{k})$ the structure factor and,

$\mathrm{F}(\mathrm{k})=\left[\sum_{i=1}^{N} f_{i}(k)\left(\sin k \mathrm{R}_{\mathrm{ci}}\right) / \mathrm{kR}_{\mathrm{ci}}\right]^{2} / \sum_{i=1}^{N} f_{i}^{2}(\mathrm{k})$ is the orientation factor for completely uncorrelated intramolecular formations, in which $R_{\mathrm{ci}}$ is the distance between the $i-t h$ atom and the gravity center of this formation and $N$ is the number of atoms. The average size of the inter- and intramolecular formation, $R]=14.8$ and $\mathrm{R} 2=7.6 \mathrm{~A}$, respectively, was estimated according to [9] $R_{i}=$ $7.73 / k_{i}-0.3$, where $k i(i=1,2)$ is the reflection location in the experimental diffraction pattern.

The first reflection at $k 1$ in $S_{\text {int }}(k)$ pattern from am-BN is described by the structure factor $S_{\mathrm{hs}}(\mathrm{k})$ of hard spheres [10]:

$$
\begin{gathered}
S_{h s}(k)=1 /\{1-\rho \tilde{c}(k)\} \\
c(k)=\left(4 \pi \sigma^{3} / b\right)\left\{\left[-2 \beta / b^{2}+24 \gamma / b^{5}\right]+\operatorname{sinb}\left[-\alpha / b^{2}+2 \beta / b^{2}+4 \gamma / b^{2}-24 \gamma / b^{4}\right]+\right. \\
\left.\operatorname{cosb}\left[-\alpha / b-\beta / b+2 \beta / b^{3}-\gamma / b+12 \gamma / b^{3}+24 \gamma / b^{5}\right]\right\}, \\
\text { where } b=k \sigma, \alpha=-(1+2 \eta)^{2} /(1-\eta)^{4}, \beta=6 \eta(1+0.5 \eta)^{2} /(1-\eta)^{4}, \\
\gamma=-0.5 \eta(1+2 \eta)^{2} /(1-\eta)^{4},
\end{gathered}
$$

$\rho$ is the density ( number of molecular formations / $\left.\AA^{3}\right), \widetilde{c}(k$ ) is the fourier-image of direct correlation function, $\eta=(\pi / 6)$ $\rho \sigma^{3}$ is the packing density, $\sigma$ is the diameter of hard sphere (molecular formation). The second reflection $k_{2}$ is due to molecular formation [10]:

$$
I_{i n}(k)=\sum_{l=1}^{N_{1}} n_{i} f_{t}(k)\left[\sum_{j=1}^{N_{2}} m_{l j} f_{l j}(k) \sin \left(k r_{l j}\right) / k r_{l j}+\alpha_{l} \bar{f}(k) \sin \left(k r_{1}\right) / k r_{1_{t}}-\rho_{0} \bar{f}(k) \int_{0}^{R_{1}} 4 \pi r^{2} \sin (k r) / k r d r\right]
$$

where $f(k)$ is the average nuclear factor of both $B$ and $N$ atoms , $\rho_{0}=\mathrm{d} / \mathrm{m}_{\mathrm{H}} \sum_{i=1}^{N} n_{i} M_{i} ; \mathrm{d}$ is the pycnometric density, $\mathrm{m}_{\mathrm{H}}$ is the weight of hydrogen atom, $M$ is the atomic weight, $R_{1}$ is the radius of sphere around the first atom outside which the atomic distribution is continuous, $r_{1}=R_{1}$ is the thickness of the shell consistent of $\alpha_{1}$ atoms of intermediate distribution, from discrete to continuous; $r_{1 j}=\left(r_{1}-r_{j}\right) \leq r 1$ is the distance between $1-t h$ and $j-t h$ atoms in discrete distribution of atoms, $l$ is the index of summation over $N 1$ atoms of different $n$ kinds chosen for the central ones around which the atoms the nearest environment in coordination spheres to be considered; $j$ is the sumation index over $\mathrm{m}$ atoms in $\mathrm{N}_{2}$ coordination spheres surrounding 1 atoms.

CONCLUSIONS 
In our case $\mathrm{C}-\mathrm{BN}$ was prepared at low pressures and temperatures. This supported the dependence $P(T)$ known for carbon [12] indicating the favored formation of cubic phase over hexagonal at the lower temperatures the lower the pressure.

Using $\rho$ we evaluated $d$ for am-BN equal to $2.66 \mathrm{~g} / \mathrm{cm}^{3}$ that appears to be higher than known $\left(2.29 \mathrm{~g} / \mathrm{cm}^{3}\right)$ density for $\mathrm{h}-\mathrm{BN}$ and less than that $\left(3.45 \mathrm{~g} / \mathrm{cm}^{3}\right)$ for $c-B N$. The valuation is performed on the basis of description of intermolecular scattering by a hard-sphere model (turbostrate, R1 $\AA$ ). Intermolecular scattering was extracted from the total one, $I^{\text {norm }}$ exp $(k)$, after that theoretical calculation of intramolecular scattering was carried out using the model structure of turbostrate as nucleus and "fringe" surrounding it [13]. The nucleus is an averaging over nuclei having both $h \cdot B N$ and $c-B N$ structures, surrounded by the "fringe" consistent of incomplete hexagonal rings $B_{6} N_{4}$ and tetrahedral $B_{4} N$ and $B_{4}$, respectively, with account of the stoichiometry of $B N$. Notice that discrete reflections from polycrystalline phases are easily extracted from the diffraction patterns of am-BN.

The am-BN layers obtained by above mentioned method have mainly turbostrate structure which is intermediate between the structures of non-crystalline and crystalline states. In addition, in these

layers $h-B N$ and $c-B N$ are revealed in polycrytalline states. Taking into account the low values of the pressure and temperature the formation of $\mathrm{c}-\mathrm{BN}$ under these conditions could not be explained by the structural transition of $h-B N$ into $c_{-}$ $B N$ in layers. We assume that $C-B N$ was formed as a condensate before the deposition on the substrate. Such a condensate appears to be skeleton fractal with framework constructed by dendrite type which, in its turn, is surrounded by "fringe".

\section{REFERENCES}

[1] Chayahara A., Yokoyama H., Imura T. et al., Jap.J.Appl.Phys., 27 (1988) 440.

[2] Akkerman Z.L., Fainer N.I., Kosinova M.L. et al,, Proc. SPIE-Int.Opt.Eng.1783 (1992) 530-540

[3] General-use X-ray diffractometer (Designed and manufactured by the "Burevestnik" Research and Production Amalgamation, Leningrad)

[4] ASTM, 26, N773.

[5] ASTM, 25, N1033.

[6] Bogatyrev V.L., Yurjev G.S.and Yakhin V.S., Rentgenografiya ionitov (Nauka, SB of USSR, Novosibirsk, 1982)

[7] Cromer T. and Waber T., Acta Crystallogr., 18 (1965) 104.

[8] Egelsnaff P.A., Pege D.J. and Powles J.G., Mol.Phys., 20 (1971) 881 .

[9] Volgboender-Tetzner G., Z.Phys., 150 (1958) 215.

[10] Wertheim M.S., Phys Rev.Lett., 10 (1963) 321; Thiele E., J.Chem.Phys., 39 (1963)175.

[11] A.I.Kitaigorodskii, X-ray structural analysis of amorphous and fine-crystalline solids (Tekh. Teor. Lit., MoscowLeningrad, 1952)p33.

[12] Bundy F.P., J.Chem.Phys. 88 (1963) 631.

[13] Kasatochkin V.I., Doklady Akad. Nauk SSSR, 36 (1952) 759; Izv.Akad.Nauk, Otd.Tekhnicheskikh Nauk, 10 (1953). 